\title{
Association between Single Nucleotide Polymorphisms in Gamma-Aminobutyric Acid B Receptor, Insulin Receptor Substrate-1, and Hypocretin Neuropeptide Precursor Genes and Susceptibility to Obstructive Sleep Apnea Hypopnea Syndrome in a Chinese Han Population
}

\author{
Zhijun Li Tingyu Tang Jianzong Du Wenjuan Wu Xiaoxi Zhou Guangyue Qin
}

Department of Respiratory Medicine, Zhejiang Hospital, Hangzhou, China

\section{Significance of the Study}

- To investigate genotype-phenotype changes associated with SNPs of rs1801278 (GABBR1), rs29230 (IRS-1), and rs9902709 (HCRT) genes in Chinese Han individuals. This study revealed that the SNPs of rs1801278 and rs29230 were susceptible markers for the increasing risk of obstructive sleep hypoapnea syndrome, but rs9902709 did not appear to be a susceptibility locus.

\section{Key Words}

Obstructive sleep apnea hypopnea syndrome .

$\mathrm{Y}$-Aminobutyric acid $\mathrm{B}$ receptor gene $\cdot$ Insulin receptor substrate-1 gene $\cdot$ Hypocretin neuropeptide precursor gene $\cdot$ Single nucleotide polymorphisms

\footnotetext{
Abstract

Objective: To investigate genotype-phenotype changes between rs29230 in $Y$-aminobutyric acid B receptor (GABBR1), rs1801278 in insulin receptor substrate-1 (IRS-1), and rs9902709 in hypocretin neuropeptide precursor (HCRT) and obstructive sleep apnea hypopnea syndrome (OSAHS) in Chinese Han individuals. Materials and Methods: A total of 130 patients with OSAHS and 136 age- and gendermatched healthy controls were enrolled in this study. A brief description of DNA extraction and genotyping is given. Mul-
}

\begin{tabular}{ll}
\hline KARGER & $\begin{array}{l}\text { ( } 2016 \text { S. Karger AG, Basel } \\
1011-7571 / 16 / 0256-0517 \$ 39.50 / 0\end{array}$ \\
E-Mail karger@karger.com & $\begin{array}{l}\text { This is an Open Access article licensed under the terms of the } \\
\text { www.karger.com/mpp }\end{array}$ \\
$\begin{array}{l}\text { Creative Commons Attribution-NonCommercial 3.0 Un- } \\
\text { ported license (CC BY-NC) (www.karger.com/OA-license), } \\
\text { applicable to the online version of the article only. Distribu- } \\
\text { tion permitted for non-commercial purposes only. }\end{array}$
\end{tabular}

tivariate unconditional logistic regression analysis adjusted for gender and age was used to estimate the associations of single nucleotide polymorphisms (SNPs) rs29230 (GABBR1), rs1801278 (IRS-1), and rs9902709 (HCRT) with OSAHS risk. Subgroup analysis was performed to evaluate differences in these SNPs among subgroups according to gender, body mass index (BMI), and severity of disease. Results: Genotype and allele frequencies of rs29230 were significantly different between cases and controls $(p=0.0205$ and $p=0.0191$, respectively; odds ratio $=0.493,95 \%$ confidence interval $=$ $0.271-0.896$ ), especially for male patients ( $p=0.0259$ and $p=0.0202$, respectively). Subgroup analysis according to BMI also revealed a significant allele difference for rs29230 between cases and controls in the overweight subgroup $(p=0.0333)$. Furthermore, allele and genotype frequencies of rs1801278 showed significant differences between cases and controls ( $p=0.0488$ and $p=0.0471$, respectively). How- 
ever, no association was observed between rs9902709 and OSAHS risk ( $p=0.2762)$, and no differences were identified in other subgroups. Conclusion: In this study, there was an association between variants of rs29230 and rs 1801278 and OSAHS risk in the Chinese Han population but not for rs9902709.

(c) 2016 S. Karger AG, Basel

\section{Introduction}

Obstructive sleep apnea hypopnea syndrome(OSAHS) is a common disorder characterized by the limitation of airflow resulting from repetitive episodes of partial or complete upper airway collapse during sleep [1]. These recurrent episodes usually lead to repetitive breathing pauses during sleep, accompanied by snoring, marked sleep fragmentation, transient hypoxia and hypercapnia, and chronic excessive daytime sleepiness [2]. While ventilation is normal in waking patients with OSAHS, sleeprelated reductions in motoneuronal activity result in collapse of the upper airway. With changing lifestyles and dietary habits, the global prevalence of OSAHS has been determined to be fairly high, and is estimated to affect up to $17 \%$ of middle-aged men and $9 \%$ of middle-aged women [3].

The pathogenesis of OSAHS is not fully elucidated at the hereditary level. However, genetic and epidemiological studies indicate that OSAHS susceptibility is associated with multiple genetic, environmental, and developmental factors [4]. The pathophysiology of OSAHS may be investigated by detecting novel genetic susceptibility markers, which could lead to the development of new preventive and curative methods. Genetic variants in- crease the risk of OSAHS due to involvement in pathways of the upper airway anatomy, airway collapsibility, ventilation, and sleep-wake control [5].

An association between Ala20Val polymorphism and C/C variant of the GABBR1 Phe658Phe polymorphism and OSAHS had been reported in Turkish individuals [6], but not for the genotype and allele frequencies of IRS-1 rs 1801278 [7]. In addition, also, an association between the $\mathrm{C}$ allele of the HCRT rs9902709 variation and OSAHS was reported in a Japanese population [8]. Hence based on these findings the objective of this study was to investigate genotype-phenotype changes between rs29230 in $\gamma$-aminobutyric acid $\mathrm{B}$ receptor (GABBR1), rs 1801278 in insulin receptor substrate-1 (IRS-1), rs9902709 in hypocretin neuropeptide precursor (HCRT) and OSAHS in Chinese Han individuals.

\section{Subjects and Methods}

\section{Subjects}

A total of 130 Han patients with OSAHS (20 females and 110 males) and 136 controls ( 24 females and 112 males) who were examined at the Sleep Disorders Center of Zhejiang Hospital (Hangzhou, China) were enrolled in this study in southeast China (fig. 1). The subjects were divided into two subgroups based on body mass index (BMI). The patient cohort consisted of 116 overweight (BMI $\geq 25$ ) and 14 normal-weight (BMI $<25$ ) individuals, while the control group comprised 92 overweight and 44 normal-weight subjects. Each of them provided a written informed consent prior to being enrolled in the study. The research was conducted in accordance with the World Medical Association Declaration of Helsinki and approved by the Ethics Committee of Zhejiang Hospital.

\section{OSAHS Diagnosis and Exclusion Criteria}

Study participants underwent diagnostic overnight polysomnography (Alice LE; Philips Respironics Inc., Murrysville, Pa.,

Fig. 1. Flowchart for subject recruitment.

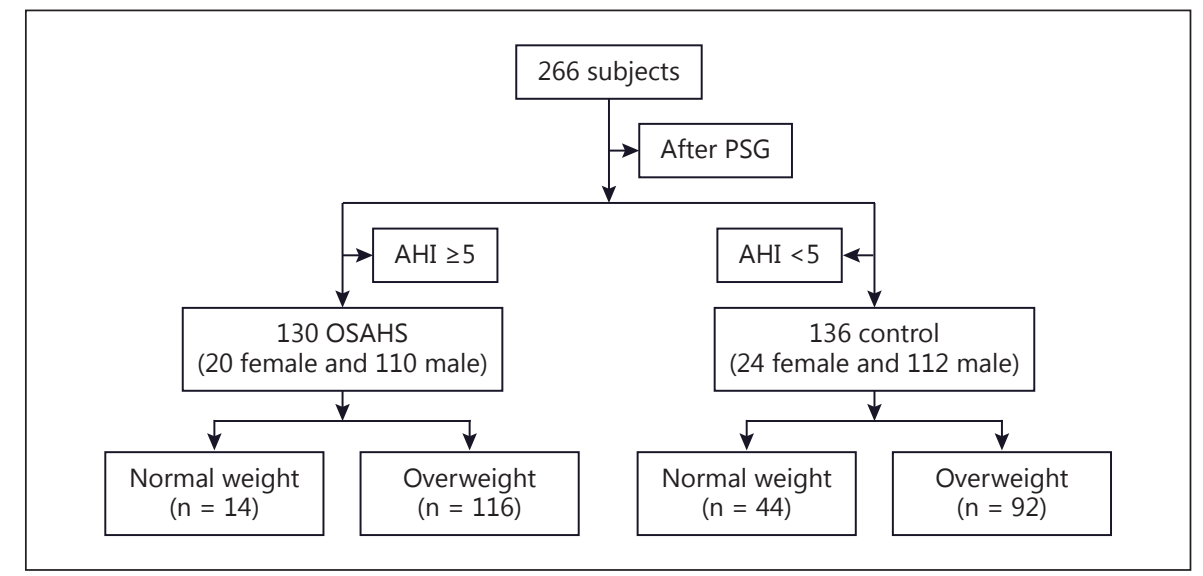
PSG $=$ Polysomnography. 
Table 1. Oligonucleotide sequences used for genotyping

\begin{tabular}{|c|c|c|c|}
\hline Gene & SNP & Allele/Primers & Sequences \\
\hline IRS-1 & $\begin{array}{l}\text { rs1801278 } \\
\text { (Homo } \\
\text { sapiens) }\end{array}$ & $\begin{array}{l}\text { Allele } \\
\text { First primer } \\
\text { Second primer } \\
\text { Extension primer }\end{array}$ & $\begin{array}{l}\text { ATGGGCAGACTGGGCCCTGCACCTCCC[G/A]GGG-CTGCTAGCATTTGCAGGCCTA } \\
5^{\prime} \text {-ACGTTGGATGATGGTCATGTAGTCACCCCG-3' } \\
5^{\prime} \text {-ACGTTGGATGGTCGAGATGGGCAGACTGG-3' } \\
5^{\prime} \text {-AAATGCTAGCAGCCC-3' }\end{array}$ \\
\hline GABBR1 & $\begin{array}{l}\text { rs } 29230 \\
\text { (Homo } \\
\text { sapiens) }\end{array}$ & $\begin{array}{l}\text { Allele } \\
\text { First primer } \\
\text { Second primer } \\
\text { Extension primer }\end{array}$ & 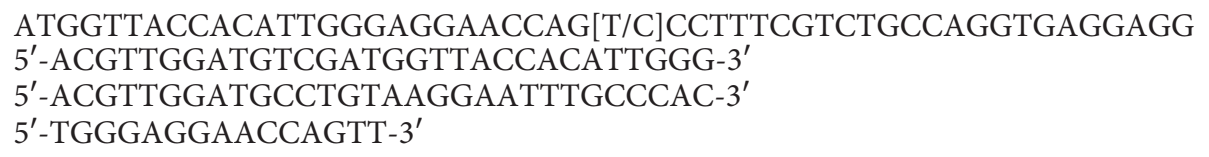 \\
\hline HCRT & $\begin{array}{l}\text { rs9902709 } \\
\text { (Homo } \\
\text { sapiens) }\end{array}$ & $\begin{array}{l}\text { Allele } \\
\text { First primer } \\
\text { Second primer } \\
\text { Extension primer }\end{array}$ & $\begin{array}{l}\text { CTCTGGGATGGTGAGTCACCCCTCC[A/G]TC-CCTGGATCTTTACCTTTGTGGAA } \\
\text { 5'-ACGTTGGATGGCCAGACACCATGAACCTTC-3' }^{\prime} \text { 5'-ACGTTGGATGTTTGCTTCTCTGGGATGGTG-3' }^{\prime} \\
\text { 5'-GGAAAGGTAAAGATCCAGGGA-3' }^{\prime}\end{array}$ \\
\hline
\end{tabular}

USA). The baseline examination comprised pulsoxymetry, electrophysiological signals (electroencephalography, electrooculography, and electromyography), electrocardiography, observation of thoracic movement and the analysis of sleep stages, snoring phases, and awakening reactions. Recordings were reviewed independently by two sleep specialists (J.D. and T.T.). Apnea was defined as the continuous cessation of airflow for $>10 \mathrm{~s}$, and hypopnea as a $\geq 50 \%$ reduction in airflow for $>10 \mathrm{~s}$ with oxygen desaturation of $\geq 4 \%$. The apnea-hypopnea index (AHI) was calculated as the total number of apnea and hypopnea events per hour of sleep. Patients were grouped according to OSAHS severity as follows: mild OSAHS (AHI 5-15 events/h), moderate OSAHS (AHI 16-30 events/h), and severe OSAHS (AHI $>30$ events/h). The exclusion criteria were: hypothyroidism, acromegaly, micrognathia, central sleep apnea, rhinitis, nasal polyposis, tonsil hypertrophy, or cardiac insufficiency; chronic obstructive pulmonary disease or interstitial lung disease; a history of drug or alcohol abuse, and depression, and any kind of treatment for OSAHS. 129 subjects were excluded accordingly.

\section{DNA Extraction and Genotyping}

Peripheral blood samples were obtained from each participant and stored at $-70^{\circ} \mathrm{C}$. The DNA was isolated from human peripheral leukocytes of whole-blood samples using the AxyPrep Blood Genomic DNA Miniprep Kit (Axygen Biosciences, Union City, Calif., USA). The single nucleotide polymorphisms (SNPs) HCRT rs9902709, GABBR1 rs29230, and IRS-1 rs1801278 were amplified using the GeneAmp PCR System 9700 (ABI Co. Ltd., New York, N.Y., USA). Primers for polymerase chain reaction (PCR) and single-base extension were designed using Assay Designers software version 3.0 (Sequenom Inc., San Diego, Calif., USA) and were processed following standard protocols for iPLEX chemistry. Primers were synthesized by Sangon Biotech Shanghai Co. Ltd. (Shanghai, China; table 1).

Multiplex PCR was performed in 5- $\mu$ l volumes containing 0.1 units of HotStar Taq polymerase (Qiagen, Hilden, Germany),
Table 2. Clinical and polysomnographic characteristics of the study subjects

\begin{tabular}{|c|c|c|c|}
\hline Variables & Patients & Controls & $\mathrm{p}$ value \\
\hline \multicolumn{4}{|l|}{ Demographics } \\
\hline Gender, $\mathrm{n}$ & & & 0.817 \\
\hline Male & $110(84.6 \%)$ & $112(82.4 \%)$ & \\
\hline Female & $20(15.4 \%)$ & $24(17.6 \%)$ & \\
\hline Mean age $\pm S D$, years & $51.78 \pm 12.24$ & $50.88 \pm 8.21$ & 0.617 \\
\hline Mean BMI $\pm \mathrm{SD}$ & $28.17 \pm 3.62$ & $25.38 \pm 3.17$ & \\
\hline Normal weight, $\mathrm{n}$ & $14(10.77 \%)$ & $44(32.35 \%)$ & 0.005 \\
\hline Overweight, $\mathrm{n}$ & $116(89.23 \%)$ & $92(67.65 \%)$ & \\
\hline Severity of disease, $\mathrm{n}$ & & & $<0.001$ \\
\hline Normal & 0 & 136 & \\
\hline Mild & $26(20 \%)$ & $\mathrm{UN}$ & \\
\hline Moderate & $22(16.92 \%)$ & $\mathrm{UN}$ & \\
\hline Severe & $82(63.08 \%)$ & $\mathrm{UN}$ & \\
\hline \multicolumn{4}{|c|}{ Polysomnography (means $\pm S D)$} \\
\hline AHI, events/h & $35.66 \pm 19.52$ & $3.43 \pm 1.12$ & $<0.001$ \\
\hline Male & $38.78 \pm 18.16$ & $3.32 \pm 2.05$ & \\
\hline Female & $25.76 \pm 15.13$ & $3.12 \pm 1.07$ & \\
\hline Overweight & $39.12 \pm 22.32$ & $4.09 \pm 1.87$ & \\
\hline Normal weight & $28.34 \pm 13.32$ & $2.89 \pm 0.97$ & \\
\hline MAI, events/h & $26.28 \pm 16.09$ & $4.87 \pm 1.56$ & $<0.001$ \\
\hline $\mathrm{LSaO}_{2}, \%$ & $74.27 \pm 11.15$ & $96.85 \pm 3.8$ & $<0.001$ \\
\hline ODI4, events/h & $43.42 \pm 25.17$ & $4.16 \pm 1.08$ & \\
\hline \multicolumn{4}{|l|}{ Sleep stages, $\%$ of TST } \\
\hline NREM1 & $54.21 \pm 18.79$ & $47.9 \pm 20.04$ & $<0.001$ \\
\hline NREM2 & $99.73 \pm 32.31$ & $92.1 \pm 36.21$ & $<0.001$ \\
\hline NREM3/4 & $60.51 \pm 19.95$ & $46.23 \pm 15.72$ & $<0.001$ \\
\hline REM & $53.23 \pm 18.31$ & $39.74 \pm 16.36$ & $<0.001$ \\
\hline
\end{tabular}

$\mathrm{LSaO}_{2}=$ Lowest oxygen saturation; MAI = microarousal index; NREM = non-rapid eye movement sleep; ODI4 = oxygen desaturation index; REM = rapid eye movement sleep; $\mathrm{SD}=$ standard deviation; $\mathrm{TST}=$ total sleep time; $\mathrm{UN}=$ unknown. 
Table 3. Allele and genotype distribution in the patients and controls

\begin{tabular}{|c|c|c|c|c|c|}
\hline Gene & Cases & Controls & $\chi^{2}$ & $\mathrm{p}$ value & OR $(95 \% \mathrm{CI})$ \\
\hline \multicolumn{6}{|c|}{ HCRT rs9902709 } \\
\hline Allele & & & 1.1857 & 0.2762 & \\
\hline A & $255(0.981)$ & $260(0.942)$ & & & \\
\hline G & $5(0.019)$ & $16(0.058)$ & & & $2.443(0.465-12.820)$ \\
\hline Genotype & & & 1.1408 & 0.5653 & \\
\hline $\mathrm{AG}$ & $5(0.038)$ & $6(0.044)$ & & & \\
\hline AA & $125(0.962)$ & $128(0.941)$ & & & \\
\hline GG & $0(0.000)$ & $2(0.015)$ & & & \\
\hline \multicolumn{6}{|c|}{$G A B B R 1$ rs 29230} \\
\hline Allele & & & 5.4914 & 0.0191 & \\
\hline $\mathrm{T}$ & $185(0.717)$ & $228(0.838)$ & & & \\
\hline C & $73(0.283)$ & $44(0.162)$ & & & $0.493(0.271-0.896)$ \\
\hline Genotype & & & 7.7729 & 0.0205 & \\
\hline $\mathrm{CC}$ & $12(0.093)$ & $0(0.000)$ & & & \\
\hline $\mathrm{TT}$ & $65(0.504)$ & $95(0.699)$ & & & \\
\hline $\mathrm{CT}$ & $52(0.403)$ & $41(0.301)$ & & & \\
\hline \multicolumn{6}{|c|}{ IRS-1 rs1801278 } \\
\hline Allele & & & 3.8819 & 0.0488 & \\
\hline A & $0(0.000)$ & $9(0.033)$ & & & \\
\hline G & $260(1.000)$ & $263(0.967)$ & & & \\
\hline Genotype & & & 3.9421 & 0.0471 & \\
\hline $\mathrm{AG}$ & $0(0.000)$ & $9(0.067)$ & & & \\
\hline GG & $130(1.000)$ & $127(0.933)$ & & & \\
\hline
\end{tabular}

$10 \mathrm{ng}$ of whole genome-amplified genomic DNA, $2.5 \mathrm{pmol}$ of each primer, and $2.5 \mu \mathrm{mol}$ of dNTP. Thermocycling was carried out at $94^{\circ} \mathrm{C}$ for $15 \mathrm{~min}$ followed by 45 cycles of $94^{\circ} \mathrm{C}$ for $20 \mathrm{~s}, 56^{\circ} \mathrm{C}$ for $30 \mathrm{~s}$, and $72^{\circ} \mathrm{C}$ for $1 \mathrm{~min}$, with a final incubation at $72^{\circ} \mathrm{C}$ for $3 \mathrm{~min}$. Unincorporated dNTPs were deactivated using 0.3 units of shrimp alkaline phosphatase (Sequenom Inc.). Primer extension was performed using $5.4 \mathrm{pmol}$ of each primer extension probe, $50 \mu \mathrm{mol}$ of the appropriate ddNTP combination, and 0.5 units of iPLEX enzyme (Sequenom Inc.). Extension reactions were carried out at $94^{\circ} \mathrm{C}$ for $15 \mathrm{~min}$ followed by 45 cycles at $94^{\circ} \mathrm{C}$ for $20 \mathrm{~s}$, then $56^{\circ} \mathrm{C}$ for $30 \mathrm{~s}$, and $72^{\circ} \mathrm{C}$ for $1 \mathrm{~min}$, and a final incubation at $72^{\circ} \mathrm{C}$ for $3 \mathrm{~min}$.

Thermocycling A cation exchange resin was used to remove residual salt from the reactions. Purified primer extension reaction products were spotted into a 384-well SpectroCHIP using the MassARRAY Nanodispenser (Sequenom Co.) and determined by a matrix-assisted laser desorption/ionization time-of-flight mass spectrometer. Genotype calling was performed in real time with MassARRAY RT software version 3.0.0.4 and analyzed using MassARRAY Typer software version 3.4.

\section{Statistical Analysis}

Continuous values were expressed as means \pm standard deviation. Hardy-Weinberg equilibrium testing was carried out for all three SNPs. Pearson's $\chi^{2}$ tests were used to compare the alleles and genotypes between cases and controls, and stratified analyses were performed to evaluate the difference of these SNPs among subgroups based on gender, BMI, and severity of disease. Odds ratios
(ORs) and 95\% confidence intervals (CIs) were obtained with Plink software (OpenLink Software Inc., Burlington, Mass., USA). $\mathrm{p}$ values $<0.05$ were considered statistically significant.

\section{Results}

\section{Characteristics of Study Subjects}

Clinical and polysomnographic characteristics of study subjects are shown in table 2 . The mean age was $51.78 \pm 12.24$ years (range $=31-67$ ) in cases and $50.88 \pm$ 8.21 years (range $=31-60$ ) in controls, Following BMI classification, 116 OSAHS patients $(89.23 \%)$ had a higher likelihood of being overweight, while, by contrast, 44 healthy subjects (32.35\%) with normal weight were more prevalent in the control group; the difference between the two groups was significant $(\mathrm{p}=0.005)$. We examined Hardy-Weinberg equilibrium in the controls and cases with observed $\mathrm{p}$ values of 0.00212 for rs $9902709,0.86024$ for rs 1801278, and 0.85051 for rs29230.

\section{Polymorphisms in Case and Control Cohorts}

For SNP rs29230, allele and genotype frequencies were $71.7 \%(\mathrm{~T}), 28.3 \%(\mathrm{C}), 9.3 \%$ (CC), $50.4 \%(\mathrm{TT})$, and 
Table 4. Allele and genotype distribution in the patients and controls both according to gender

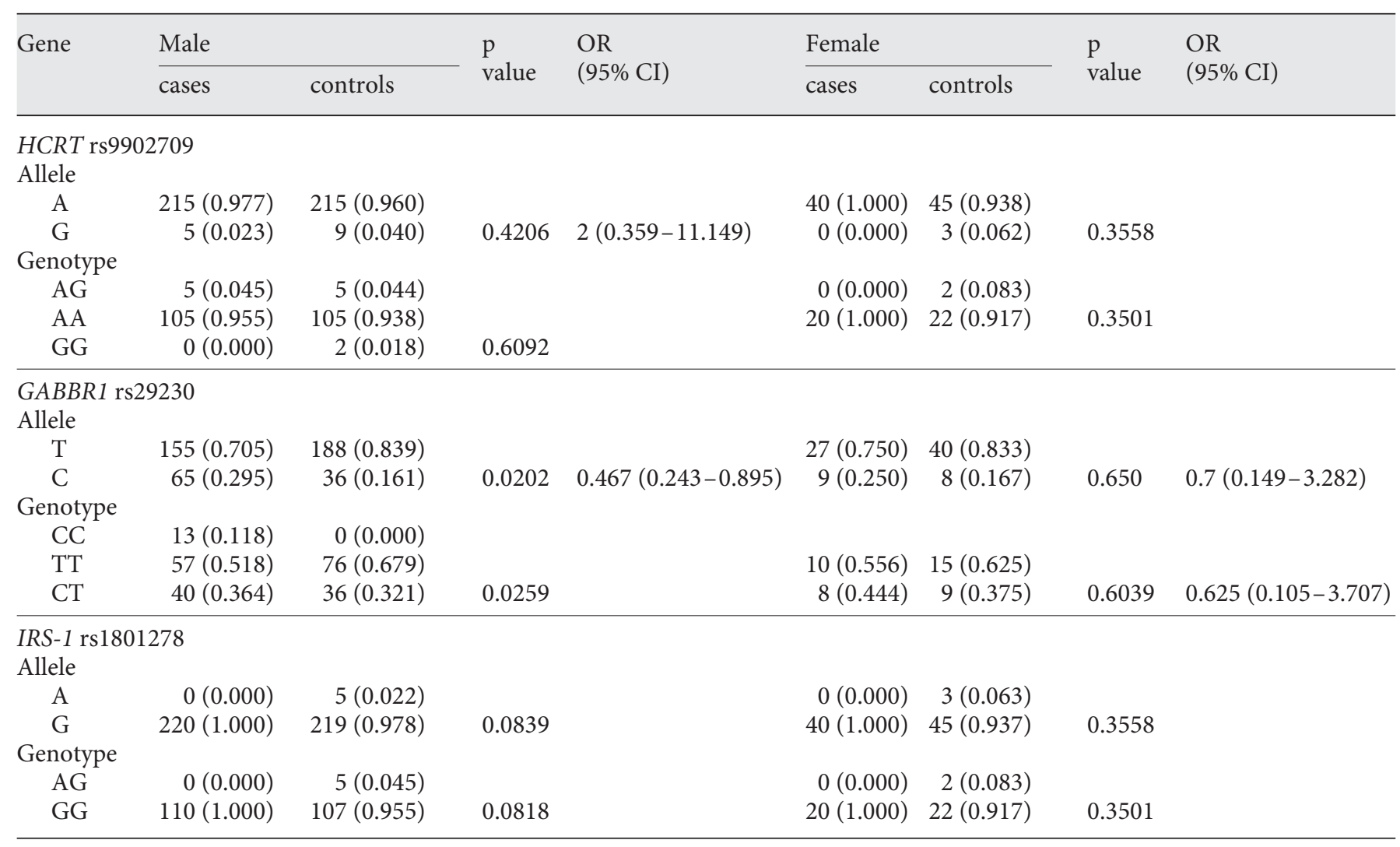

40.3\% (CT) in patients, and $83.8 \%(\mathrm{~T}), 16.2 \%(\mathrm{C}), 69.9 \%$ (TT), and $30.1 \%$ (CT) in controls; differences were significant between the two groups $\left(\chi^{2}=5.4914, \mathrm{p}=0.0191\right.$, $\mathrm{OR}=0.493,95 \% \mathrm{CI}=0.271-0.896$, and $\chi^{2}=7.7729, \mathrm{p}=$ 0.0205 ), indicating that possession of the $\mathrm{C}$ allele is associated with susceptibility to OSAHS (table 3 ). To further explore allele and genotype frequency differences, the subgroup analysis demonstrated that the allele and genotype distributions of rs 29230 were $70.5 \%(\mathrm{~T}), 29.5 \%(\mathrm{C})$, $11.8 \%$ (CC), $51.8 \%$ (TT), and $36.4 \%$ (CT) in male patients, and $83.9 \%(\mathrm{~T}), 16.1 \%(\mathrm{C}), 67.9 \%(\mathrm{TT}), 32.1 \%$ (CT), and $0 \%$ (CC) in male controls, indicating that possession of at least one $\mathrm{C}$ allele is significantly more frequent in patients than controls $(\mathrm{p}=0.0202$, $\mathrm{OR}=0.467$, $95 \% \mathrm{CI}=0.243-0.895$, and $\mathrm{p}=0.0259$; table 4 ). However, no differences were identified between female patients and controls (table 4). Likewise, the C allele of rs 29230 was more prevalent in cases than controls in the overweight subgroup $(\mathrm{p}=0.0333, \mathrm{OR}=0.487,95 \% \mathrm{CI}=$ 0.250-0.951; table 5).
For rs1801278 variants, only the $\mathrm{G}$ allele was detected in cases, with A and G alleles present in controls; a significant difference was observed between cases and controls $\left(\chi^{2}=3.8819, p=0.0488\right.$; table 3$)$. Moreover, the GG genotype was significantly more common in patients than controls $\left(\chi^{2}=3.9421, p=0.0471\right.$; table 3$)$. However, subgroup analysis according to gender, BMI and severity of disease indicated that no significant associations with OSAHS risk were identified (tables 4-6).

Allele and genotype frequencies of rs9902709 were 98.5\% (A), 1.5\% (G), 3.1\% (AG), and 96.9\% (AA) in cases, and $96.3 \%(\mathrm{~A}), 3.7 \%(\mathrm{G}), 4.4 \%(\mathrm{AG}), 94.1 \%(\mathrm{AA})$, and $1.5 \%(\mathrm{GG})$ in controls; the lack of significance between the two groups indicates that rs9902709 variants are not involved in the etiology of OSAHS $\left(\chi^{2}=1.1857, \mathrm{p}=\right.$ 0.2762 , OR $=2.443,95 \% \mathrm{CI}=0.465-12.82$, and $\chi^{2}=$ $1.1408, \mathrm{p}=0.5653$; table 3 ). Furthermore, stratified analysis according to gender, BMI, and severity of disease also revealed no associations with OSAHS (tables 4-6). 
Table 5. Allele and genotype distribution in the patients and controls according to BMI

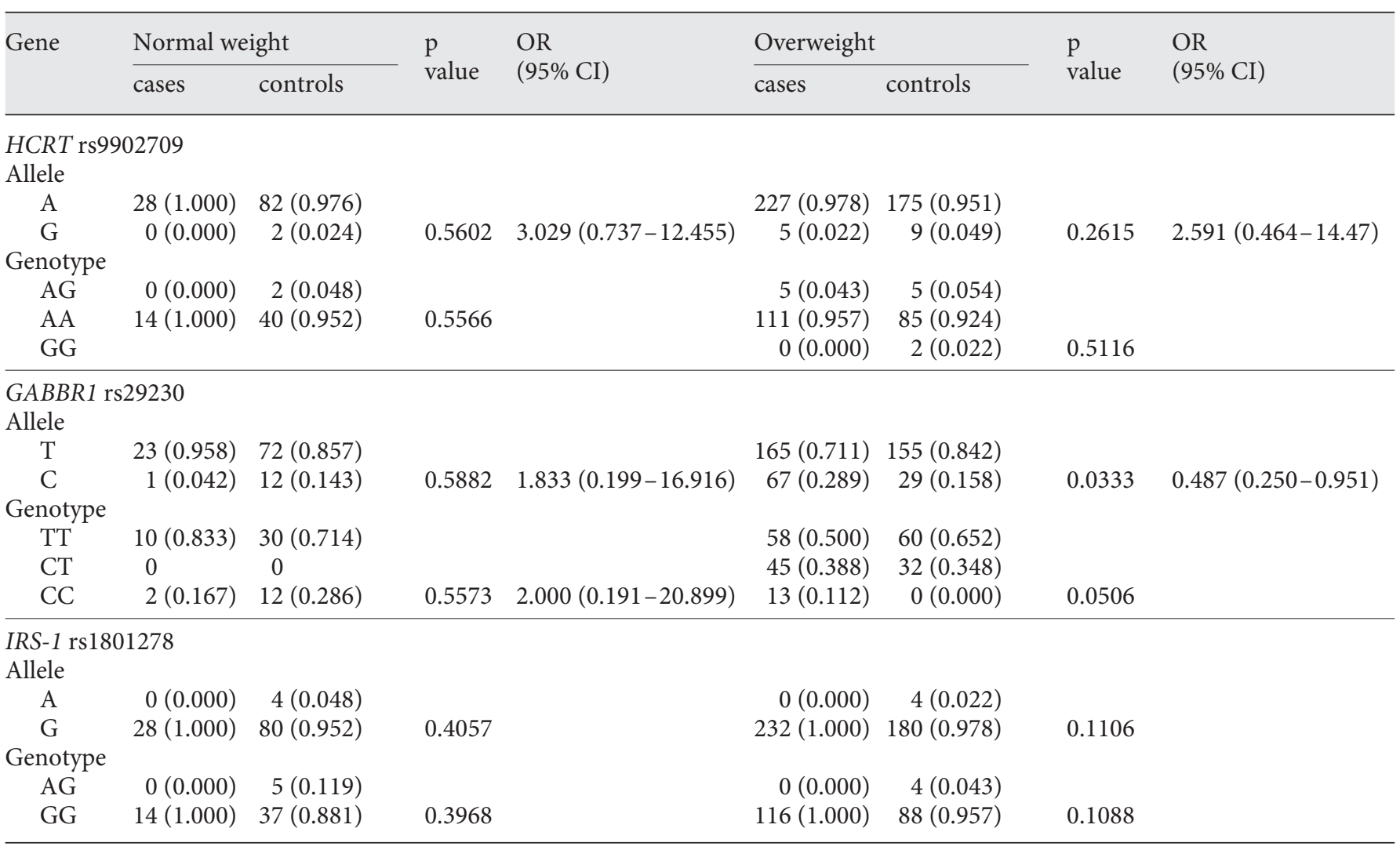

\section{Discussion}

The present study showed that the SNPs GABBR1 rs29230 and IRS-1 rs1801278 were susceptibility candidates for OSAHS in Chinese Han individuals. However, no association between HCRT rs9902709 and OSAHS was revealed.

The patency of the upper airway during respiration is controlled mostly by muscle activity, which also prevents collapse due to negative airway pressure [9]. Hypoglossal motoneurons are cholinergic elements that innervate tongue muscles and play important roles during respiration. Dysfunction of the hypoglossal motoneurons appears to be implicated in OSAHS [10]. The hypoglossal motor nucleus releases GABA, which has an important physiological function through its association with a large family of receptors, including the metabotropic $\mathrm{GABA}_{\mathrm{B}}$ receptor [11]. This is encoded by GABBR1, which maps to chromosome 6 , contains 22 exons, and spans at least $18 \mathrm{~kb}[12,13]$. It is therefore conceivable that $G A B B R 1$ variations correlate with the etiology of OSAHS.
Our present study showed significant differences in GABBR1 SNP rs29230 between OSAHS cases and controls $(\mathrm{p}=0.0205)$, especially in male and overweight patients, which was concordant with those reports. The previous research by Bayazit et al. [6] showed that GABBR1 polymorphisms are associated with the occurrence of OSAHS in the Turkish population. However, the overweight individuals in OSAHS patients were more prevalent than healthy controls, which may increase the possibility of obtaining spurious findings because an increased body weight can cause the development of OSAHS. Nevertheless, our findings and previous studies indicate that $G A B B R 1$ is a susceptibility locus for OSAHS, independently of ethnic background and environmental agents.

Our present study also identified a strong association between the IRS-1 rs1801278 G allele or GG genotype and an increased risk of developing OSAHS in the Chinese Han population. To the best of our knowledge, the association between OSAHS and type 2 diabetes mellitus and insulin resistance is independent of obesity [14]. The IRS is the main substrate of insulin receptor tyrosine kinase, 
Table 6. Allele and genotype distribution in OSAHS according to severity of disease

\begin{tabular}{|c|c|c|c|c|c|c|c|c|c|c|c|c|}
\hline Gene & \multicolumn{2}{|l|}{ OSAHS } & $\begin{array}{l}\mathrm{p} \\
\text { value }\end{array}$ & $\begin{array}{l}\text { OR } \\
(95 \% \text { CI })\end{array}$ & \multicolumn{2}{|l|}{ OSAHS } & $\begin{array}{l}\mathrm{p} \\
\text { value }\end{array}$ & $\begin{array}{l}\text { OR } \\
(95 \% \mathrm{CI})\end{array}$ & \multicolumn{2}{|l|}{ OSAHS } & $\begin{array}{l}\mathrm{p} \\
\text { value }\end{array}$ & $\begin{array}{l}\text { OR } \\
(95 \% \mathrm{CI})\end{array}$ \\
\hline \multicolumn{13}{|c|}{ HCRT rs9902709 } \\
\hline \multicolumn{13}{|c|}{ Allele } \\
\hline A & $52(1.000)$ & $44(1.000)$ & & & $52(1.000)$ & $159(0.970)$ & & & $44(1.000)$ & $159(0.970)$ & & \\
\hline G & $0(0.000)$ & $0(0.000)$ & & & $0(0.000)$ & $5(0.030)$ & 0.4215 & & $0(0.000)$ & $5(0.030)$ & 0.4595 & \\
\hline \multicolumn{13}{|c|}{ Genotype } \\
\hline \multicolumn{13}{|c|}{ GABBR1 rs29230 } \\
\hline \multicolumn{13}{|c|}{ Allele } \\
\hline $\mathrm{T}$ & $45(0.865)$ & $31(0.705)$ & & & $45(0.865)$ & $105(0.675)$ & & & $31(0.705)$ & $105(0.675)$ & & \\
\hline $\mathrm{C}$ & $7(0.135)$ & $13(0.295)$ & 0.3123 & $\begin{array}{c}2.063 \\
(0.499- \\
8.530)\end{array}$ & $7(0.135)$ & $55(0.325)$ & 0.0924 & $\begin{array}{c}2.648 \\
(0.827- \\
8.478)\end{array}$ & $13(0.295)$ & $55(0.325)$ & 0.6398 & $\begin{array}{c}1.284 \\
(0.450- \\
3.663)\end{array}$ \\
\hline \multicolumn{13}{|c|}{ IRS-1 rs1801278 } \\
\hline \multicolumn{13}{|c|}{ Allele } \\
\hline G & $52(1.000)$ & $44(1.000)$ & & & $52(1.000)$ & $164(1.000)$ & & & $44(1.000)$ & $164(1.000)$ & & \\
\hline \multicolumn{13}{|c|}{ Genotype } \\
\hline GG & $26(1.000)$ & $22(1.000)$ & & & $26(1.000)$ & $82(1.000)$ & & & $22(1.000)$ & $82(1.000)$ & & \\
\hline
\end{tabular}

and represents a key element in the actions of insulin and insulin-like growth factor. The IRS family consists of 4 closely related members, and IRS-1 on chromosome $2 \mathrm{q}$ has been regarded as a plausible susceptibility locus for insulin resistance in type 2 diabetes mellitus. Among the known IRS-1 polymorphisms, associations were previously observed with diabetes mellitus, cancer, multiple myeloma, and Alzheimer's disease [15-18]. However, Bayazit et al. [6] reported no significant differences in the genotype and allele frequencies of IRS-1 rs1801278 between OSAHS patients and controls overall, but IRS- 1 variants in male Turkish patients appeared to be susceptible to OSAHS development via a gender-specific comparison [7], which was inconsistent with our finding. The discrepancy between our results and the previous study could be attributed to ethnic or environmental factors, so further studies are needed to verify the findings.

Additionally, the current research demonstrated that no association between rs9902709 variants and OSAHS was identified in Chinese Han individuals. Based on our results, it seems reasonable to speculate that HCRT variants are not involved in the development of OSAHS. The previous study reported that circulating hypocretin levels were significantly lower in OSAHS patients than controls, and inversely correlated with the severity of OSAHS [19, 20]; however, a clinical trial by Ahmed et al. [8] had previously found that the frequency of the HCRT rs9902709 variation increased HCRT expression, and was associated with a decreased risk for OSAHS in the Japanese population. These differences between the two studies may be primarily attributed to environmental factors which have the potential to interact with the genetic background.

The present study had two limitations: the sample size was relatively small and OSAHS patients were more likely to be overweight than controls, which might have increased the chance of obtaining spurious findings. Future analysis should investigate a larger sample size, and include these risk factors.

\section{Conclusion}

The present study showed that SNPs rs1801278 and rs29230 were associated with an increased risk of OSAHS, and that HCRT did not appear to be a susceptibility gene for OSAHS. 


\section{Acknowledgment}

We thank Mr. Wei Cai's team for their excellent technical support.

\section{Disclosure Statement}

There is no conflict of interest.

\section{References}

1 Young T, Peppard PE, Gottlieb DJ: Epidemiology of obstructive sleep apnea. A population health perspective. Am J Respir Crit Care Med 2002;165:1217-1239.

2 Young T, Palta M, Dempsey J, et al: The occurrence of sleep-disordered breathing among middle-aged adults. N Engl J Med 1993;32:1230-1235.

$\checkmark 3$ Peppard PE, Young T, Barnet JH, et al: Increased prevalence of sleep-disordered breathing in adults. Am J Epidemiol 2013; 177:1006-1014.

4 Palmer LJ, Buxbaum SG, Larkin E, et al: A whole-genome scan for obstructive sleep apnea and obesity. Am J Hum Genet 2003;72: 340-350.

5 Redline S, Tishler PV: The genetics of sleep apnea. Sleep Med Rev 2000;4:583-602.

-6 Bayazit YA, Yilmaz M, Kokturk O, et al: Association of GABA(B)R1 receptor gene polymorphism with obstructive sleep apnea syndrome. ORL J Otorhinolaryngol Relat Spec 2007;69:190-197.

7 Bayazit YA, Erdal ME, Yilmaz M, et al: Insulin receptor substrate gene polymorphism is associated with obstructive sleep apnea syndrome in men. Laryngoscope 2006;116:19621965.
8 Ahmed WA, Tsutsumi M, Nakata S, et al: A functional variation in the hypocretin neuropeptide precursor gene may be associated with obstructive sleep apnea syndrome in Japan. Laryngoscope 2012;122:925-929.

-9 Van Lunteren E: Muscles of the pharynx: structural and contractile properties. Ear Nose Throat J 1993;72:27-29.

$\checkmark 10$ Donato R, Nistri A: Relative contribution by GABA or glycine to $\mathrm{Cl}(-)$-mediated synaptic transmission on rat hypoglossal motoneurons in vitro. J Neurophysiol 2000;84:27152724.

11 O'Brien JA, Berger AJ: Cotransmission of GABA and glycine to brain stem motoneurons. J Neurophysiol 1999;82:1638-1641.

12 Goei VL, Choi J, Ahn J, et al: Human gamma aminobutyric acid B receptor gene: complementary DNA cloning, expression, chromosomal location, and genomic organization. Biol Psychiatry 1998;44:659-666.

13 Grifa A, Totaro A, Rommens JM, et al: GABA (gamma-amino-butyric acid) neuro-transmission: identification and fine mapping of the human GABA-B receptor gene. Biochem Biophys Res Commun 1998;250:240-250.

14 Harsch IA, Schahin SP, Radespiel-Tröger M, et al: Continuous positive airway pressure treatment rapidly improves insulin sensitivity in patients with obstructive sleep apnea syndrome. Am J Respir Crit Care Med 2004;169: 156-162.
15 Alharbi KK, Khan IA, Munshi A, et al: Association of the genetic variants of insulin receptor substrate 1 (IRS-1) with type 2 diabetes mellitus in a Saudi population. Endocrine 2014;47:472-477.

16 Zhang $\mathrm{H}$, Wang A, Ma $\mathrm{H}$, et al: Association between insulin receptor substrate 1 Gly972Arg polymorphism and cancer risk. Tumour Biol 2013;34:2929-2936.

17 Birmann BM, Tamimi RM, Giovannucci E, et al: Insulin-like growth factor-1- and interleukin-6-related gene variation and risk of multiple myeloma. Cancer Epidemiol Biomarkers Prev 2009; 18:282-288.

18 Wang W, Yang L, Tan L, et al: Arg972 insulin receptor substrate-1 polymorphism and risk and severity of Alzheimer's disease. J Clin Neurosci 2014;21:1233-1237.

19 Aksu K, Firat Güven S, Aksu F, et al: Obstructive sleep apnoea, cigarette smoking and plasma orexin-A in a sleep clinic cohort. J Int Med Res 2008;37:331-340.

20 Sakurai S, Nishijima T, Takahashi S, et al: Low plasma orexin-A levels were improved by continuous positive airway pressure treatment in patients with severe obstructive sleep apnea hypopnea syndrome. Chest 2005;127: 731-737. 